\title{
François Proïa, Le voyage de Julien Gracq. Géopoétique et mélancolie de l'histoire
}

\section{Michela Gardini}

\author{
(2) OpenEdition \\ Journals \\ Edizione digitale \\ URL: http://journals.openedition.org/studifrancesi/963 \\ DOI: 10.4000/studifrancesi.963 \\ ISSN: 2427-5856 \\ Editore \\ Rosenberg \& Sellier

\section{Edizione cartacea} \\ Data di pubblicazione: 1 agosto 2015 \\ Paginazione: 409-410 \\ ISSN: 0039-2944

\section{Notizia bibliografica digitale} \\ Michela Gardini, «François Proïa, Le voyage de Julien Gracq. Géopoétique et mélancolie de I'histoire », \\ Studi Francesi [Online], 176 (LIX | II) | 2015, online dal 01 août 2015, consultato il 18 septembre 2020. \\ URL : http://journals.openedition.org/studifrancesi/963; DOI : https://doi.org/10.4000/studifrancesi. \\ 963
}

Questo documento è stato generato automaticamente il 18 settembre 2020.

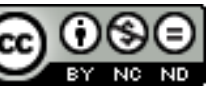

Studi Francesi è distribuita con Licenza Creative Commons Attribuzione - Non commerciale - Non opere derivate 4.0 Internazionale. 


\title{
François Proïa, Le voyage de Julien Gracq. Géopoétique et mélancolie de l'histoire
}

\author{
Michela Gardini
}

\section{NOTIZIA}

FRANçOIS PROÏA, Le voyage de Julien Gracq. Géopoétique et mélancolie de l'histoire, Napoli, Edizioni Scientifiche Italiane, 2014, pp. 136.

1 François Proïa ripercorre il viaggio in Italia di Julien Gracq, riservando particolare attenzione alla città di Roma a partire dal testo Autour des sept collines, pubblicato nel 1988, senza peraltro trascurare quanto Gracq scrisse anche riguardo a Venezia e Firenze. Un viaggio compiuto nel 1976, a sessantasei anni, a testimoniare la mancanza di «un sentiment d'urgence véritablement fébrile», per citare le parole dello stesso Gracq (p.10). Non è certo la fretta, quindi, a spingere lo scrittore verso la Penisola, quanto piuttosto la consapevolezza di appartenere a una tradizione, quella già tracciata, fra gli altri, da Stendhal e Chateaubriand. Se Gracq viene inserito di diritto, dall'autore, tra gli scrittori della letteratura di viaggio e tra i protagonisti del Grand Tour, accanto proprio a Stendhal e Chateaubriand ma anche ai pittori vedutisti quali Claude Gelée, Canaletto, Hubert Robert, del cui immaginario è inevitabilmente tributario lo sguardo di Gracq, tuttavia Proïa sottolinea l'originalità dello scrittore, nonché il superamento di una visione di matrice ancora settecentesca e ottocentesca. Da una parte, il fatto che Gracq sia stato per trent'anni professore di geografia e storia spiega il fascino esercitato su di lui dai luoghi; dall'altra, l'influenza sulla sua scrittura della poetica surrealista arricchisce lo sguardo del geografo di visioni oniriche e fantastiche. In quest'ottica, come riferisce Proïa citando le parole stesse di Gracq, la carta geografica si trasfigura in «un objet vraiment magique» (p. 30), a maggior ragione se si tratta di una carta geologica: «J'ai gardé toujours - scrive Gracq - le plus possible 
de ces cartes géologiques chez moi. Je les ouvre de temps en temps, pas toujours dans un but scientifique, loin de là. C'est un très bel objet; oui, un objet magique» (p. 30).

Di fronte ai luoghi reali, alle città italiane spesso foriere di disincanto, lo scrittore, ritrovando in questo l'ispirazione del romanziere, finisce per compiacersi della prefigurazione della fine delle città, della loro deflagrazione, proprio come quella che aveva immaginato nel romanzo Le Rivage des Syrtes (1951). La peregrinazione di Gracq sembra scaturire dal desiderio di ritornare ad un paesaggio primitivo, tanto naturale quanto minerale. Un paesaggio in cui il tempo della storia si sia fermato, lontano dagli avvicendamenti urbanistici delle città moderne. Il viaggio in Italia di Gracq diventa, in ultima analisi, pretesto per la scrittura, assurgendo a compensazione rispetto al manque della realtà.

3 Il saggio, composto di nove capitoli, è introdotto da una Prefazione di Emanuele KANCEFF. 